\title{
Studies on Pathogenicity Effect of Aeromonas hydrophila Infection in Juvenile Red Hybrid Tilapia Oreochromis sp.
}

\author{
Hamid $\mathrm{NH}^{1}$, Hassan $\mathrm{MD}^{1}$, Md Sabri MY ${ }^{3}$, Hasliza $\mathrm{AH}^{2}$, Hamdan $\mathrm{RH}^{4}$, Afifah $\mathrm{MNF}^{1}$, Raina MS ${ }^{1}$, \\ Nadia $\mathrm{ABS}^{1}$, Fuad $\mathrm{MM}^{1}$ \\ ${ }^{1}$ Department of Veterinary Clinical Studies, Faculty of Veterinary Medicine \\ Universiti Putra Malaysia, 43400 Serdang, Selangor, Malaysia \\ ${ }^{2}$ Department of Pre-Clinical Sciences, Faculty of Veterinary Medicine \\ Universiti Putra Malaysia, 43400 Serdang, Selangor, Malaysia \\ ${ }^{3}$ Department of Veterinary Pathology \& Microbiology Faculty of Veterinary Medicine \\ Universiti Putra Malaysia, 43400 Serdang, Selangor, Malaysia \\ ${ }^{4}$ Department of Clinical Studies, Faculthy of Veterinary Medicine, Universiti Malaysia Kelantan \\ Locked Bag 36, Pengakalan Chepa, 16100 Kota Bharu, Kelantan, Malaysia \\ hassanmd@upm.edu.my
}

\begin{abstract}
This study was conducted to evaluate the ability of motile Aeromonas species (MAS) to induce clinical symptoms and some pathological changes in juvenile red hybrid tilapia. A standard dose of infection was selected based on predetermined $\mathrm{LD}_{50}$. Infected fish were observed for any clinical sign and symptom for 96 hours. Samples of liver, spleen and kidney were collected for histopatological changes due to Aeromonas hydrophila infection. Clinical signs of fish included abnormal swimming behaviour and loss of balance. Most of infected fish suffered from haemorrhagic eyes and lesions on the body surface. Some of the them also developed bilateral exophthalmia. Histopathological changes were observed in kidney, liver and spleen. The infected liver showed severe congestion of hepatic veins and vacuoles formation while anterior kidney manifested degeneration of excretory tubules and glomeruli followed by severe haemorrhages and hyaline droplets degeneration. Spleen on the other hand showed tissues degeneration and vacuoles formation. All targated tissues also showed deposition of haemosiderin pigments followed by proliferation of melanomacrphage centres. Development of such symptoms was associated with the infection with Aeromonas hydrophila. The current study has shown that MAS could serve as the primary cause of severe infection not only in red hybrid tilapia but may also infected other freshwater fish species. The results of histological analysis of various tissues indicates a direct correlation between disease infection and histopathological disorders observed in the tissues.
\end{abstract}

Key Words: Aeromonas hydrophila, Red Hybrid Tilapia, Histopathology, Melanomacrophage Centres

\section{INTRODUCTION}

In the mid of 1980's, red tilapia (Oreochromis sp.) was first introduced in Malaysia and becoming one of the most important freshwater aquaculture industries since it has potential economic value and highly international demand (Azeli 2007). However, several diseases has been identified in tilapia farming. Even though Aeromonas hydrophila infection (also known as Motile Aeromonas Septicaemia, MAS) is considered to be secondary infection, it is widely known as one of most important pathogen that can cause disease outbreak of variety size of fish species and responsible for huge economic losses. Hence, most Asian countries including Malaysia rank A. hydrophila infection as one of the most economically important disease.

A. hydrophila causes disease in fish known as Motile Aeromonas Septicemia (MAS), Hemorrhagic Septicemia, Ulcer Disease, or Red-Sore Disease (Yardimci \& Aydin 2011). There are many other names of this disease which relate to the lesions caused by this bacterium including septicemia where the bacterial toxins are present within numerous 
organs of the fish, and ulcers of the fish's skin (Yardimci \& Aydin 2011; Janda \& Abbott 2010). A. hydrophila is an ubiquitous gram-negative rod-shaped bacterium which is commonly isolated from fresh water ponds and it is a normal inhabitant of the gastrointestinal tract of the fish. The disease caused by this bacterium primarily affects freshwater fish such as catfish, several species of bass, and many species of tropical or ornamental fish (Yardimci \& Aydin 2011; Janda \& Abbott 2010).

Majority of reserchers have considered A. hydrophila to be an opportunistic pathogen. Opportunistic pathogen usually do not cause disease unless other factors are involved. Which means, A. hydrophila is always capable of producing disease if given the chance such as when fish are stress due to poor handling or poor water quality. Although tilapia was first considered to be hardy and resistant to disease, but in unfavorable conditions, it can lead to mortality due to secondary infection (Laith AR \& Najiah M 2013). This problem was consequently revealed the presence of Gram-negative A. hydrophila; the most common bacteria isolate from infected organs. Thus, the aim of this study was to examine the clinical symptoms and some pathological changes in Oreochromis sp due to A. hydrophila infection.

\section{MATERIAL AND METHODS}

\section{Experimental fish}

Juvenile red hybrid tilapia (Oreochromis sp.) of mixed sexes $(30.2 \pm 0.66 \mathrm{~g})$ were obtained from the private farm in Tasik Idaman, Selangor, Malaysia. They were transferred, maintained and acclimatized to water conditioned in 1 ton tank at Aquatic Animal Health Unit (AAHU), Faculty of Veterinary, University Putra Malaysia, Serdang Selangor, Malaysia. The fish were randomly stocked into 501 aquaria for the experiment. They were fed ad-libitum with a commercial feed and monitored for health condition. Feeding were terminated 24 hours before the experiment, and the fish were starved during the experiment period.

\section{Preparation of bacterial suspension}

A. hydrophila was purely cultured on TSA agar at $35^{\circ} \mathrm{C}$ for 24 hours prior to the experiment. A fresh culture of the bacteria was carefully scraped and mixed with $10 \mathrm{ml}$ sterile physiological saline.The bacterial suspension was adjusted untill turbidity was the same as in the $\mathrm{LD}_{50}$ value which is $6.3 \times 10^{6} \mathrm{cfu} / \mathrm{ml}$ by using spectrophotometer.

\section{Experimental infection}

A total of 20 fish were exposed by intraperitoneal injection with $0.1 \mathrm{ml}$ of live $A$. hydrophila. All injected fishes were released into the aquarium and observed for 96 hours.

\section{Sampling}

Fish were monitered for abnormal behavior and clinical symtoms every 24 hours until 96 hours. All moribund fish were removed from the tank daily and subjected for bacterial isolation. Samples of liver, spleen and kidney were collected for histology purposes to observe the patological changes due to A. hydrophila infection. 


\section{Histology}

After experimentally infected with A. hydrophila, the fish were dissected and samples of liver, spleen and kidney were taken. The organs were removed and fixed in 10\% buffered formalin for at least 72 hours. Then, the fixed tissues were processed using automatic tissue processing involving dehydration, clearing and wax infiltration process. The whole process took about 24 hours to finish. The tissues were then embedded in paraffin wax. Then, the embedded tissues were cut into $4-5 \mu \mathrm{m}$ by using rotary microtome. The thin sections were then stained with the standard haematoxylin and eosin and mounted on clean glass slides.They were allowed to dry overnight and the cell structures were observed by light microscope (Nikon, Eclipse, E 800).

\section{RESULTS AND DISCUSSION}

\section{Gross clinical signs}

All morbid fish showed multiple types of clinical signs such as abnormal swimming behaviour and loss of balance or sometimes with haemorrhagic eyes, while some other fish developed bilateral exophthalmia (Figure 1). The body surface of the fish were found to suffer erosion of the pectoral fins and development red-white lesions that were extended up to the caudal fin. Anal region and the fin bases also showed inflamed areas. Upon dissection of the freshly dead and infected fish, the spleen and kidney were observed to be swollen, while liver were found to be pale and rough with petechiation (Figure 1).

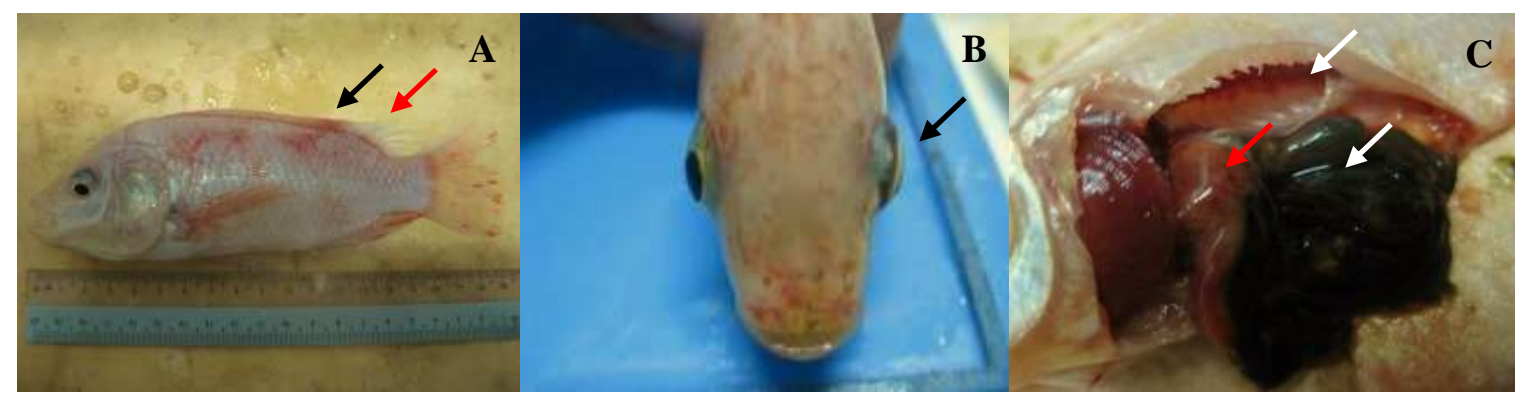

Figure 1.(A) Juvenile red tilapia infected with A. hydrophila at 1 dpi showing marked clinical signs such as lesions (black arrow) and fins erosion (red arrow); (B) Injected fish at 2 dpi showed clinical sign of bilateral exophthalmia (black arrow); and (C) Internal organs of juvenile red hybrid tilapia at 1 dpi showed petechiation of liver (red arrow), enlargement of spleen and kidney (white arrow)

\section{Histopathology}

Some histopathological changes were observed in kidney, liver and spleen. Microscopic examination of the kidney showed degenerative changes with severe hemorrhages and extensive necrosis excretory tubules and glomeruli cells. The lumina of tubules contained degenerated tubular epithelial cells with hyaline droplets accumulation and infiltration of lymphocytic cells (round cells with large blue staining nuclei) were clearly visible. (Figure 2). In liver tissues, congestion of hepatic veins, vacuolation were and moderate lymphocytic infiltration was also observed in liver (Figure 3). Microscopic examination of spleen tissues showed severe degenerative changes with extensive necrosis and vacuolar formation. All tissues (kidney, spleen, and liver) showed the presences of 
hemosiderin which were then proliferated into melanomacrophage centers (MMC) (Figure 2, 3 and 4).

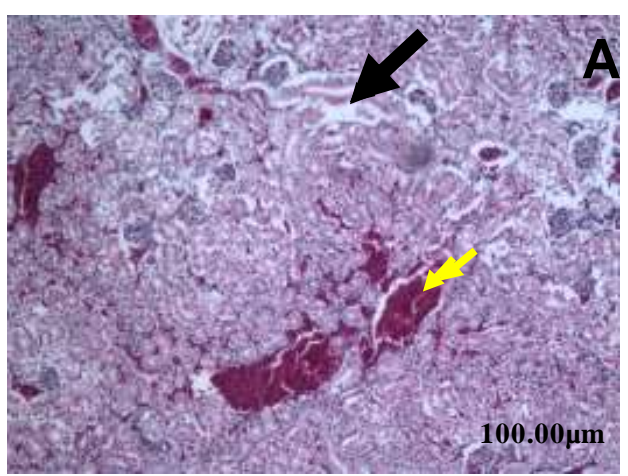

Figure 2.(A) Kidney of infected fish at 1 dpi glomeruli (black arrow), severe haemorrhages (yellow arrow); and (B) Presence of MMC (hemosiderin) (red arrow), lymphocitic infiltration (blue arrow) and hyaline droplets (green arrow) (H\&E staining, 10×)
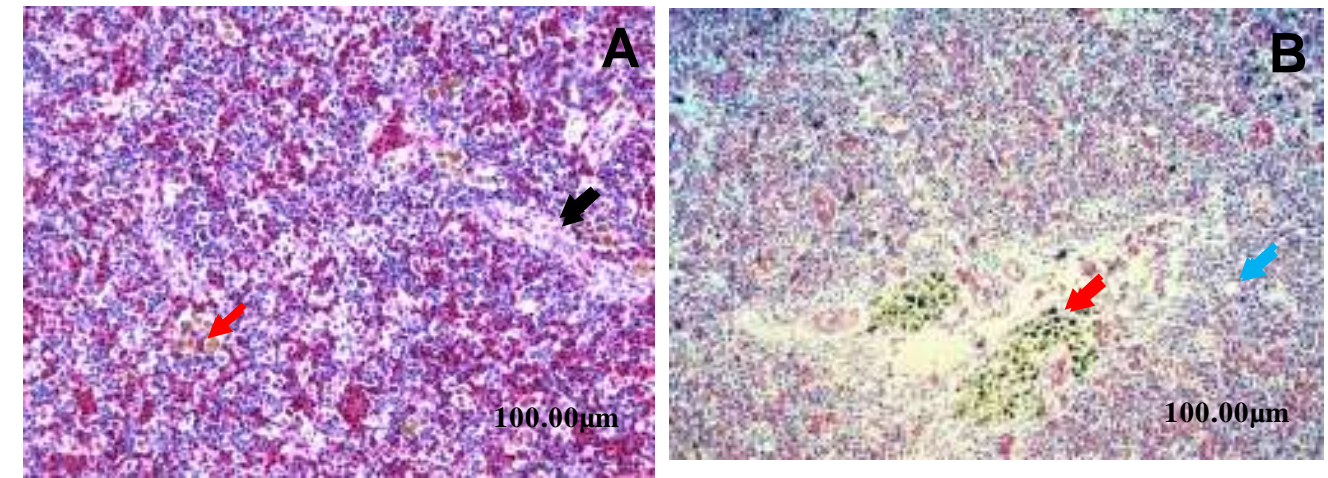

Figure 3. (A) Spleen from infected fish at 1 dpi showing tissue degeneration (black arrow); and (B) Presence of MMC (hemosiderin) (red arrow) in the parenchyma and vacuolation (blue arrow) (H\&E staining, 10x)
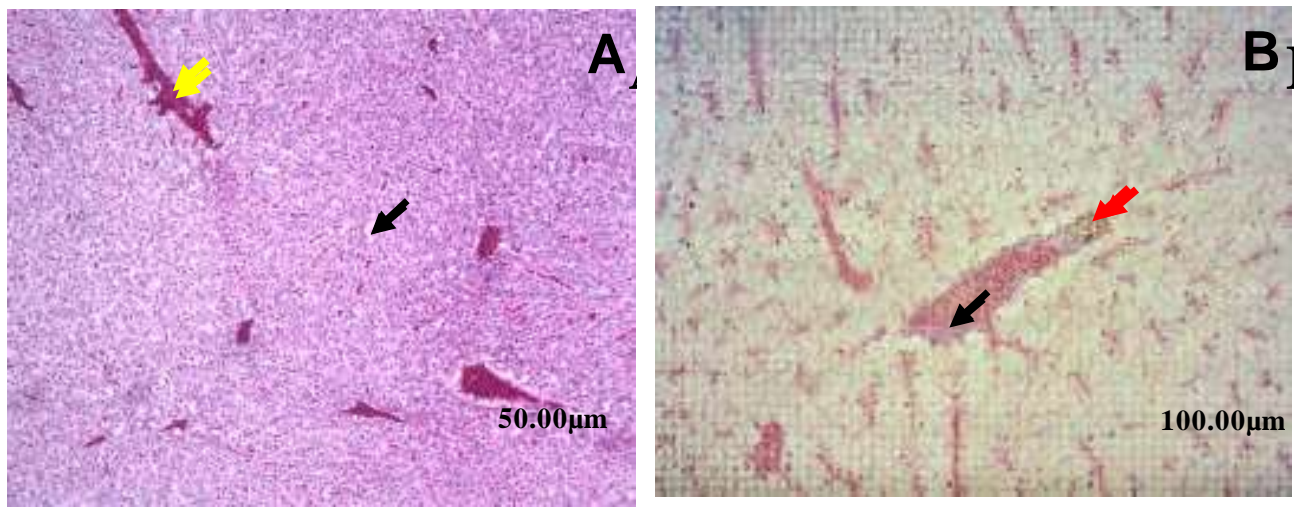

Figure 4.(A) Liver of infected fish at 1 dpi showing severe congestion of hepatic veins (yellow arrow) and severe vacuolation (black arrow) (H\&E staining, 5x); (B) Liver of infected fish at 1 dpi showing lymphocitic infiltration of hepatic veins (black arrow), haemorrhages and also presence of MMC (hemosiderin) (red arrow) (H\&E staining, 10x) 


\section{Discussion}

Although motile aeromonads have received much bad reputation as fish pathogen, it is essential to note that these bacteria also are part of the normal intestinal microflora of healthy fish. Hence, the presence of these bacteria is not always indicating of disease infection. Inevitably, stress is frequently considered as one of the factor contributing to disease outbreaks by these bacteria (Laleh et al. 2015). In the present study, after 24 hours post-infection, juvenile red hybrid tilapia showed several clinical symptoms such as abnormal swimming behaviour and aggregated on the water surface. Others appeared to be loss of escape reflex and sluggish. The body surface of the fish were found to suffer lesions and erosion especially at the pectoral fins and development of red-white lesions that could extended up to the caudal fins were also evident. Anal region and the fin bases also developed red discolouration and haemorrhages of the eyes while some fish also developed bilateral exophthalmia. These results may be due to bacterial toxins. Noor El Deen et al. (2013) stated that the bacteria caused acute mortality among infected fishes in which the most visible clinical signs included exophthalmia in one or both eyes. The common gross pictures observed in the freshly dead and infected fish were enlargement of kidney and spleen. The liver were also found to be pale, swollen with petechiation and rough. This may occur due to septicaemia reaction of MAS. These results agreed with the findings by Noor El-Deen et al. (2014), Kaleeswaran et al. (2012), Islam et al. (2008) and Fang et al. (2000).

In the current study, kidney tissues showed severe degeneration of excretory tubules and glomerular, hyaline deposition and severe haemorrhages in the intertubular and glomerular areas. Not only that, severe congestion of hepatic veins and haemorrhages, followed by vacuoles formation were found in liver of infected fish. In an earlier study about pathological findings of experimental $A$. hydrophila infection in Nile tilapia (Oreochromis niloticus) by Yardimci \& Aydin (2011), the most significant findings were observed in liver and kidney which were also supported by other researchers as well (Subharthi Pal et al. 2015; Sun et al. 2014). They observed some pathological alteration in kidney such as interstitial haemorrhage, tissues degeneration and necrosis of the tubular epithelia which were almost similar with the present study. These pathological changes were said to be related with interstitial nephritis. Interstitial nephritis is a form of nephritis that affecting the interstitium of the kidneys surrounding the tubules which may affect the kidney's function. (Roberts 2001). Not only that, in liver tissues, the vacuoles formation and necrosis in hepatocytes cells were also evident. According to Kurtović et al. (2008), degeneration of vacuolar epithelial is as a result of lysosomal distension or swelling. The reason of the vacuolation and necrosis of the liver were reported to be associated with toxins and extracellular products such as haemolysin, protease and elastase produced by $A$. hydrophila (Laith \& Najiah 2013; Afifi et al. 2000). Apparently, this organs were striked by toxins produced by the bacterial and loses its structural orientation which were further concurrently supported by the current study. The hyaline droplets which were found in kidney were likely constituted with protein reabsorbed from the glomerular filtrate after being contaminated by bacterial toxin (Jiraungkoorskul et al. 2002). Moderate aggregation of lymphocytic infiltration were also observed in kidney, liver and spleen. Lymphocytes are recognised as immuno-competent cells that commonly related to immune response of the fish towards infection.

In the present study, kidney, spleen and liver tissues have the presence of hemosiderin which proliferated into MMC. According to Couillard et al. (1999), MMC may contain four types of brown pigments known as melanin, lipofuscin, ceroid and hemosiderin. Cipriano (2001) reported earlier that an acute septicemia will target liver and kidneys. 
These organs are striked by bacterial toxins and will lose their normal structural (Huizinga et al. 1976). These toxins induced more severe tissue alteration and cause the development of disease in fish (Chopra et al. 2005). One of the most typical characteristic clearly show in this study was hemosiderin. In the present study, all tissues showed abundant presence of numerous hemosiderin granules (brownish yellow) producing a condition known as hemosideriosis. This phenomenon was caused by an increasing rate of destruction erythrocytes in the organs, which resulted in a decrease amount of mature erythrocytes in the circulating system (Hibiya 1982). The condition might also developed in association with chronic inflammatory lesions (Agius \& Roberts 2003). According to Miyazaki and Kaige (1985), histopathology of motile aeromonad septicemia in carps (Carassius auratus), the hemosiderin deposition in the spleen was reported. Wolke et al. (1985), first suggested that MMC as a potential indicator to monitors of fish health.

\section{CONCLUSION}

Results from the current experiment clearly showed A. hydrophila is a serious bacterial pathogen which was found to be highly infectious in juvenile red hybrid tilapia. Due to the highly potential pathogenicity of $A$. hydrophila to fish, proper action should be taken into consideration for the effective control of this bacteria through the administration of appropriate antibiotic, or other therapeutic means such as probiotics, immunostimulants and immunoadjuvants, and also by improving the diagnostic standard through the use of advanced molecular technique.

\section{ACKNOWLEDGEMENT}

This work was supported by University Putra Malaysia. The help of the staff from the Aquatic Animal Health Unit, Faculty of Veterinary Medicine, University Putra Malaysia are gratefully acknowledged.

\section{REFERENCES}

Afifi SH, Al-Thobiati S, Hazaa MS. 2000. Bacteriological and histopathological studies on Aeromonas hydrophila infection of nile tilapia (Oreochromis niloticus) from fish farms in Saudi Arabia. Assiut Vet Med J. 84:195-205.

Agius C, Roberts RJ. 2003. Melano-macrophage centers and their role in fish pathology. J Fish Dis. 26:499-509.

Azeli A. 2007. Potensi besar ternakan tilapia. KOSMO: 19th July 2007. p. 9.

Cipriano RC. 2001. Aeromonas hydrophila and motile aeromonad septicemias of fish. Eriim tarihi. 11: 7.

Chopra AK, Xu XJ, Ribardo D, Gonzalez M, Kuhl K, Houston CW. 2000. The cytotoxicenterotoxic of Aeromonas hydrophila induces proinflammatory cytokine production and activates arachidonic acid metabolism in macrophages. J Infect Immun. 68:2808-2818.

Couillard CM, Williams PJ, Courtenay SC, Rawn GP. 1999. Histopathological evaluation of Atlantic tomcod (Microgadus tomcod) collected at estuarine sites receiving pulp and paper mill effluent. Aquatic Toxicol. 44:263-278.

Datta Ray S, Homechaudhuri S. 2013. Non-specific immune response in Indian major carp, Catla catla against A. hydrophila infection. J App Sci Technol Cult Issues. 79:507-511. 
Takahashi E, Ozaki H, Fuji Y, Kobayashi H, Yamanaka H. 2014. Properties of hemolysin and protease produced by Aeromonas trota. PlosOne. 9:e91149. DOI:10.1371/journal.pone. 0091149.

Fang HM, Ling KC, Ge R, Sin YM. 2000. Enhancement of protective immunity in blue gourami Trichogaster trichopterus (Pailas), against Aeromonas hydrophila and Vibrio anguillarum by A. hydrophila major adhesin. J Fish Dis. 23:137-145.

Hibiya T. 1982. An atlas of fish histology, normal and pathological features. Stuttgart (Germany): Fischer. p. 64-65.

Huizinga HW, Esch GW, Hazen TC. 1979. Histopathology of red-sore disease Aeromonas hydrophilain naturally and experimentally infected largemouth bass Micropterus salmoides (Lacépéde). J Fish Dis. 2:263-277.

Islam MT, Mamnur Rashid M, Mostafa K. 2008. Histopathological studies of experimentally infected shing, Heteropneustes fossilis with Aeromonas hydrophila bacteria. Progress Agric 19:89-96.

Janda J M, Abbott SL. 2010. The Genus aeromonas: Taxonomy, pathogenicity, and infection. Clin Microbiol Rev. 23:35-73.

Jiraungkoorskula W, Upatham ES, Kruatrachue M, Sahaphong S, Vichasri-Grams S, Pokethitiyook P. 2002. Histopathological effects of roundup, a glyphosate herbicide, on nile tilapia (Oreochromis niloticus) herbicide, on nile tilapia (Oreochromis niloticus). Sci Asia. 28:121127.

Kaleeswaran B, Ilavenil S, Ravikumar S. 2012. Changes in biochemical, histological and specific immune parameters in Catla catla (Ham) by Cynodondactylon (L). J King Saud Univ Sci. 24:139-152.

Kumar R, Pande V, Singh L, Sharma L, Saxena N. (2016) Pathological findings of experimental Aeromonas hydrophila infection in golden mahseer (Tor putitora). Fish Aquacult J. 7:160. DOI:10.4172/2150-3508.1000160.

Kurtović B, Teskeredžić E, Teskeredžić Z. 2008. Histological comparison of spleen and kidney tissue from farmed and wild European sea bass (Dicentrarchus labrax L). Acta Adriat. 49:147-154.

Laith AR, Najiah M. 2013. Aeromonas hydrophila: Antimicrobial susceptibility and histopathology of isolates from diseased catfish, Clarias gariepinus (Burchell). J Aquacult Res Dev. 5:215.

Laleh YG, Mohammad EJZ, MiLad A. 2015. The study on effect of temperature stress on occurrence of clinical signs caused by Aeromonas hydrophila in Capoeta damascinain in vitro condition. J Adv Anim Vet Sci. 3:406-412.

Miyazaki T, Kaige N. 1985. A histopathological study on motile aeromonad disease of crucian carp. Fish Pathol. 21:181-185.

Noor El-Deen AE, Dorgham SM, Hassan AHM, Hakim AS. 2014. Studies on Aeromonas hydrophila in cultured Oreochromis niloticus at Kafr El Sheikh Governorate, Egypt with reference to histopathological alterations in some vital organs. World J Fish Mar Sci. 6:233240.

Noor El Deen AE, Shalaby SI, Zaki MS, Abd Elzaher MF. 2013. Some infectious and non infectious eye affection syndrome in fish. Life Sci J 10:1362-1368.

Roberts RJ. 2001. The bacteriology of teleosts. In: Roberts RJ, editor. Fish pathology. Philadelphia (USA): WB Saunders. p. 315-321. 
Shahi N, Mallik SK, Sahoo M, Das P. 2013. Biological characteristics and pathogenicity of a virulent Aeromonas hydrophila associated with ulcerative syndrome in farmed rainbow trout, Oncorhynchus mykiss (Walbaum), in India. Isr J Aquacult. 39:11.

Pal P, Ray SD, Homechaudhuri S. 2015. Evaluation of in vivo non-specific immunity and oxidative stress in Labeo rohita (Hamilton, 1822) infected with Aeromonas hydrophilaas biomarker for early diagnosis. Int J Fish Aquat Stud. 3:116-124.

Sun S, Zhu J, Jiang X, Li B, Ge X. 2014. Molecular cloning, tissue distribution and expression analysis of a manganese superoxide dismutase in blunt snout braem Megalobrama amblycephala. Fish Shellfish Immunol J. 38:340-347.

Wolke REG, George CJ, Blazer VS. 1985. Pigmented macrophage accumulations (MMC, PMB): Possible monitors of fish health. In: Hargis WJ, editor. NOAA Technical Report NMfS 25. Washington DC (USA): NOAA. p. 93-97.

Yardimci B, Aydin Y. 2011. Pathological findings of experimental Aeromonas hydrophila infection in nile tilapia (Oreochromis niloticus). Ankara Üniv Vet Fak Derg. 58:47-54. 